\title{
Science Academies' Refresher Course on Advances in Molecular Biology
}

\author{
in collaboration with \\ Department of Microbiology \& Cell Biology, Division of Biological Sciences, Indian Institute of \\ Science, Bengaluru \\ 8-22 December 2017
}

Sponsored by

Indian Academy of Sciences, Bengaluru

Indian National Science Academy, New Delhi

The National Academy of Sciences, India, Allahabad

Applications are invited from faculty (preferably less than 45 years of age) teaching undergraduate and/or postgraduate courses in colleges and/ or universities. The number of seats available is 10 for local and 20 for outstation participants. The applicants must enclose CV with a brief statement on why he/she is interested in this course. The application must be duly forwarded by the Head of the Department/Chairman/Principal with a commitment that the candidate if selected, will be provided leave/OOD for the duration of the course. The selected candidates will be provided with round-trip bus/train (III AC) fare by the shortest route and local hospitality during the course. Applications should be submitted ONLINE by clicking the following link: http: //web-japps.ias.ac . in: 8080/Refreshcourse/RAMB . jsp Course Director: Prof. Umesh Varshney, Chairman, Division of Biological Sciences, Department of Microbiology and Cell Biology, Indian Institute of Science, Bengaluru.

Coordinators: (1) Prof. Saumitra Das, Department of Microbiology and Cell Biology, Indian Institute of Science, Bengaluru. (2) Prof. H A Ranganath, Visiting Professor, Division of Biological Sciences, Indian Institute of Science, Bengaluru.

(A) Lectures: Nucleic acids and chromatin structure; Nucleic acids transactions - Replication, Transcription and Translation regulation; Ribosome biogenesis; Protein structure and function; Molecular immunology; Genetic Recombination and DNA Repair; Biology of RNA - splicing, editing, microRNAs, Ribozyme; molecular oncology; Genes in development and differentiation; Epigenetics and gene regulation; molecular biology of viruses; Restriction enzymes and modifications; Genetic engineering; Neurobiology; Bioinformatics- structural, functional and comparative genomics; Metagenomics; Genome editing; Big-data biology; Synthetic genomes. Evolution of genomes; Molecular basis of evolution \& its associated theories.

(B) Practicals: 1) Nucleic acids isolation, detection and quantification; 2) Site directed mutagenesis;

3) Protein expression and purification; 4$)$ Reporter gene activity assays ( $\beta$-galactosidase activity or luciferase activity) Proposed resource persons: Faculty members from the Indian Institute of Science and other institutions in Bengaluru.

\section{Last date for receipt of application: 10 October 2017}

Contact address: Dr T D Mahabaleswara, Coordinator (RC/LW), Indian Academy of Sciences, C.V. Raman Avenue, Sadashivanagar, Bengaluru 560080 (Email: sep@ias.ac.in). 